\title{
ApPLICATION OF GIS IN EPIZOOTIOLOGICAL SURVEILLANCE OF SWINE TRICHINELLOSIS IN ONE ENDEMIC DISTRICT IN SERBIA ${ }^{1}$
}

\author{
ZIVOJINOVIC M.*, SOFRONIC-MILOSAVLJEVIC LJ.**, RADOJICIC S.*** \& KULISIC Z.***
}

\section{Summary:}

Application of new tools for epizootiological investigations in veterinary medicine, such as Geographical Information Systems (GIS), offers a new approach and possibilities for the eradication or control of infectious diseases. GIS is particularly useful for research conducted in small areas strongly impacted by man. Trichinellosis is a world-wide zoonosis, which is endemic in some European countries, Balkan district and Serbia in particular. There are very few data on GIS application in the field of trichinellosis. We here present the application of GIS for mapping Trichinella spp. occurrence and spatial and temporal patterns of Trichinella infection in one endemic district in Serbia. Settlements with trichinellosis were marked and particular points of interest were designated. Data on prevalence of Trichinella infection in domestic swine accompanied by location of foci indicated the existence of disease geographical stationarity. This first report on GIS application in Serbia will facilitate trichinellosis surveillance and monitoring of Trichinella spp. circulation among domestic pigs, and populations of synanthropic and sylvatic animals.

KEY WORDS: GIS (Geographical Information Systems), epidemiology, trichinellosis, Trichinella spp., swine, veterinary medicine.

B oth animal and human trichinellosis cause serious health, economic and social problems in Serbia, where its re-emergence has been noted since the nineties (Cuperlovic et al., 2005). In the Branicevo district, the re-emergence of trichinellosis was officially recognized in 1999 and in 2003, when six of its eight municipalities, including Pozarevac, Veliko Gradiste, Golubac, Kucevo, Malo Crnice and Zabari,

\footnotetext{
* Specialistic Veterinary Institute "Pozarevac", Dunavska 89, 12000 Pozarevac, Serbia.

** Institute for the Application of Nuclear Energy - INEP, University of Belgrade, Belgrade, Serbia.

**** Faculty of Veterinary Medicine, University of Belgrade, Belgrade, Serbia.

Correspondence: Milan Zivojinovic

Tel.: +381 12554840 - Fax: +381 12554940

E-mail: povetinst_milenaz@hotmail.com

${ }^{1}$ This article is based on an oral communication given at the international conference "Parasitic zoonoses in present day Europe", Belgrade, 18-20 November 2009.
}

Résumé : UTILISATION DU SIG DANS LA SURVEILLANCE ÉPIDÉMIOLOGIQUE DE LA TRICHINELLOSE DU PORC DANS UNE RÉGION ENDÉMIQUE DE SERBIE

Les nouveaux outils utilisés dans les enquêtes épidémiologiques en médecine vétérinaire, comme les Systèmes d'information géographique (SIG), apportent de nouvelles possibilités d'éradication ou de contrôle des maladies infectieuses. Le SIG est particulièrement utile pour les recherches menées dans de petites zones fortement impactés par l'homme. La trichinellose est une zoonose d'extension mondiale, endémique dans quelques pays européens, notamment des Balkans et en particulier en Serbie. II y a très peu de données sur l'utilisation des SIG dans le domaine du suivi épidémiologique de cette parasitose. Nous présentons ici I'utilisation du SIG pour cartographier Trichinella spp. et son incidence, et pour élaborer des modèles spatio-temporels dans une région endémique de Serbie. Les zones d'endémicité ont été repérées et des données d'intérêt relevées. Cette première application d'un SIG en Serbie facilitera la surveillance de la trichinellose et le suivi de la circulation de Trichinella spp. chez le porc domestique et les populations animales synanthropiques et sylvatiques.

MOTS CLÉS : SIG (Système d'information géographique), épidémiologie, trichinellose, Trichinella spp., porc, médecine vétérinaire.

were officially declared as endemic for Trichinella infection in domestic pigs and control measures were established (Zivojinovic et al., 2008). The district of Branicevo is located between $44^{\circ} 04^{\prime} 50^{\prime \prime}-44^{\circ} 49^{\prime} 20^{\prime \prime}$ north latitude and between $21^{\circ} 02^{\prime} 30^{\prime \prime}-22^{\circ} 03^{\prime} 30^{\prime \prime}$ east longitude. The total area of this district is $38.555 \mathrm{~km}^{2}$, of which $62.5 \%$ is used for agriculture. According to the data collected in the field, the prevalence of trichinellosis in domestic pigs was fluctuating during the last 15 years, reaching a peak of $0.56 \%$ in 2000 (data not published). The Veterinary Institute in Pozarevac therefore prepared a control program, which was executed by local veterinary services. Continuous control efforts in the entire endemic area have resulted in a significant decrease of Trichinella infection, to a level of $0.19 \%$ in the last five years (data not published). The district of Branicevo is surrounded by four districts within Serbia, where the prevalence of trichinellosis in swine was between $0.048 \%$ and $0.1 \%$ in 2008 , and borders with Romania, where according to published data it was approximately $0.08 \%$ between 1997 and 2004 (Blaga et al., 2009). 
The application of Geographical information system (GIS) is very valuable in veterinary parasitology for study designs, territorial sampling and drawing disease maps (Rinaldi et al., 2006). Recognized as an important tool, GIS has recently been applied for the surveillance of trichinellosis in Serbia. This paper reports on this first application of GIS in Serbia, in the Branicevo district, which covered territorial sampling and drawing maps with locations of settlements with Trichinella infected swine, industrial swine farms, slaughterhouses and hunting sections, all of which are relevant for the improvement of infection control.

\section{MATERIALS AND METHODS}

IS combines various information sources in a - spatial context allowing for the determination of mutual relationships and influences in a particular time frame. In the above described endemic district in Serbia, epizootiological surveillance of swine trichinellosis was performed using data from the Animal Notification System, veterinary services, laboratory results, geographical and epizootiological surveillance data.

\section{ANIMAL NOTIFICATION SYSTEM (ANS)}

This system provided the following data: farm ID unique farm identification number; name, address and ID of the owner, staff and person in charge of the animals (unique identification number of person); the type of farm (for fattening or reproduction); principal farm species and its production capacity; number of all households (with their ID) which raise swine in a particular settlement. Access to the ANS system was possible only from veterinary station, ambulance or institute, and by licensed person e.g. veterinary inspectors.

\section{VETERINARY SERVICES DATA}

They include parasitological examination by trichinoscopy along with data on examining veterinarian (with unique ID). In case of a doubtful finding, or in case that the sample was inadequate in size and/or muscle type, the owner was instructed to supply the regional Veterinary Institute with a new, adequate sample. In case of a positive finding, information was submitted to the veterinary inspector. It is mandatory by Serbian veterinary regulations (Official Journal of SRJ, 20/1995) for all activities to be recorded (official forms filled by veterinarian containing name of owner, address, and swine ear tag number).

\section{LABORATORY DATA}

They included results of direct parasitological investigation (trichinoscopy and artificial digestion, according to the ISO 17025; Recommendations of ICT http://monsite. wanadoo.fr/intcomtrichinellosis/page $5 . \mathrm{html}$; and Manual for diagnosis of Trichinella infection of animal - OIE, 2008), and serology (by ELISA). Epizootiological surveillance was based on serological examination of all swine in households where a Trichinella infected animal was located.

\section{GEOGRAPHICAL DATA}

They included location (latitude, longitude) of farm / premises where Trichinella infection has been detected, object relationship (proximity of piggeries to stagnant water, water currents, garbage dumps), points of interest - proximity of main roads, hunting sections, forests with wild animals, industrial farms and slaughterhouses - all collected by application of GARMIN MapSource (Garmin, Taiwan) that contains maps, waypoints, routes and track.

\section{SURVEILLANCE DATA}

Epizootiological data were obtained by a questionnaire which included data on the type of farm, number and species of all animals on farm, swine age category, type of production (fattening or reproduction), breeding conditions, presence of stagnant water, water currents in the backyard and near the backyard, contact with swine from other husbandries or with wild animals, whether breeding of swine was the only occupation of the owner, feeding practices (whether swine are fed with scraps or whether they have access to free ranging), former parasitological examinations of slaughtered swine from the same farm, existence of Trichinella infected swine in the yard, anti-helminthic treatment of swine.

\section{RESULTS}

patial and temporal patterns of Trichinella infection were made for the Branicevo district during 2008. Of the total of 189 settlements in Branicevo district, 67 (35.45\%) were recognized for the presence of Trichinella infected swine (Fig. 1 A). The prevalence of Trichinella infected swine was estimated per municipality and ranged from 0 to $1.65 \%$, with a peak in $\mathrm{M}$. Crnice (Fig. 1 B). Three large industrial swine farms (where no cases of Trichinella infected swine were registered), and twelve slaughterhouses (10 large industrial and two smaller ones) were marked (Fig. 2 A). The obtained composite provides a good foundation for future epizootiological research on risk analysis and monitoring of Trichinella free farms. In addition, all 15 hunting sections in the endemic area have been marked (Fig. 2 B), which will allow for investigations 

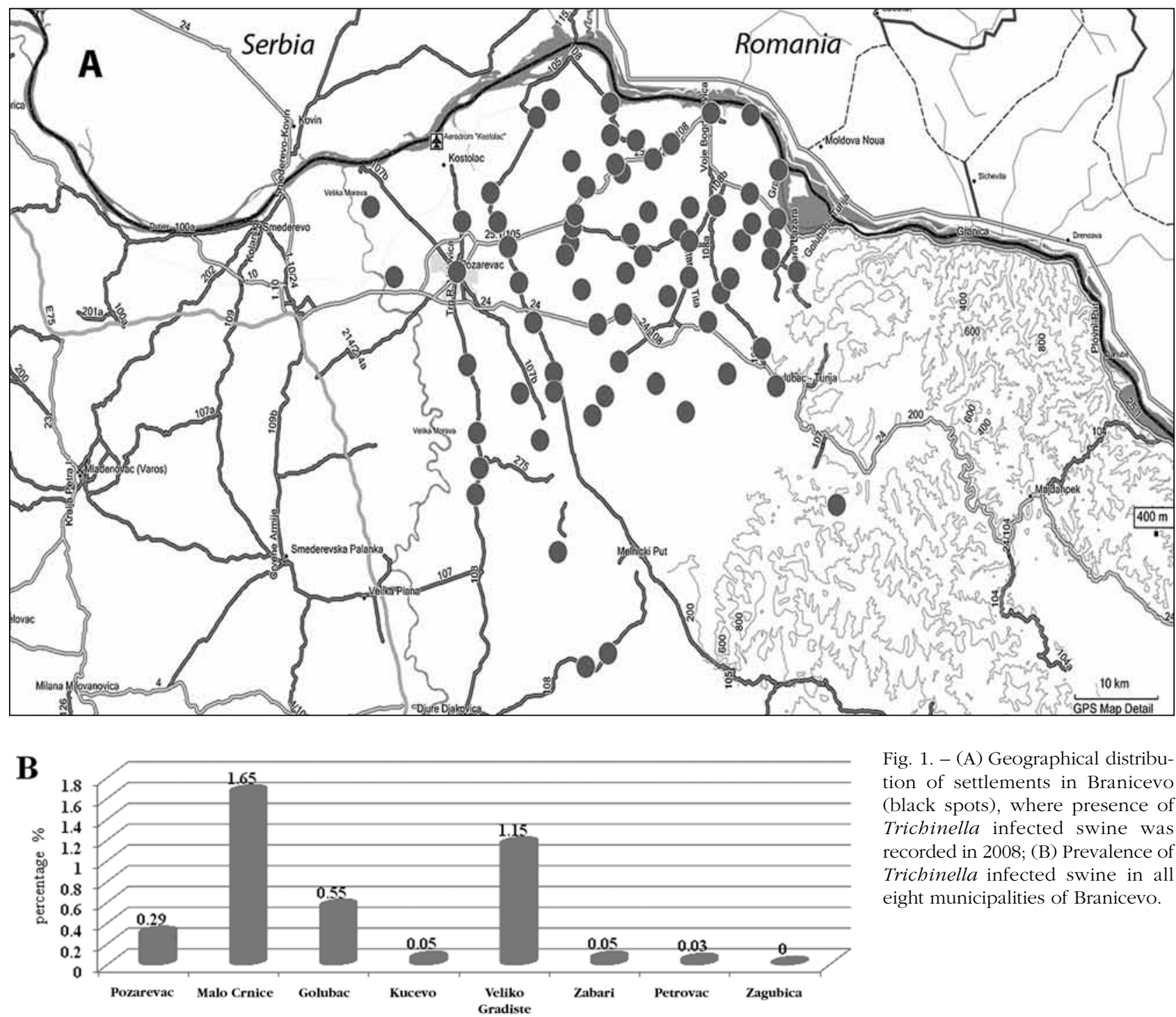

Fig. 1. - (A) Geographical distribution of settlements in Branicevo (black spots), where presence of Trichinella infected swine was recorded in 2008; (B) Prevalence of Trichinella infected swine in all eight municipalities of Branicevo.

of Trichinella infection in wild animals, necessary for monitoring parasite flow between the domestic and sylvatic cycles.

\section{DISCUSSION}

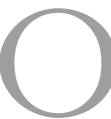

ne of the most powerful benefits of GIS is its ability to integrate different databases into a single environment (Rinaldi et al., 2006a, b). Possibilities of improving control programs for infectious diseases by using GIS methods and linking human and animal data for zoonoses have been described by Haghdoost et al. (2007). Rinaldi et al. (2006a) applied GIS for planning of sampling as well as for evaluation and presentation of findings of canine parasites as potential zoonotic agents. This quite new and insufficiently used method was only sporadically applied in field of trichinellosis. The use of GIS method for locating potential Trichinella infection high-risk foci was documented by Burke et al. (2008) in case of pasture-raised domestic pigs in USA; the presented data showed GIS application to be very useful in endemic districts strongly impacted by man. This system enables mapping of trichinellosis and development of descriptive disease maps, as well as study of the most relevant environmental features such as topography, vegetation, landcover/land use statistics, surveillance and monitoring of animal diseases, and prediction of disease occurrence. Valuable data have been provided by recent investigations, in which specifically constructed GIS was used to describe the spatial distribution and ecological pattern of T. spiralis and T. britovi in Europe (Pozio et al., 2009). The authors noted lack of data for Trichinella spp. and host species distribution and/or habitat characteristics (due to small number of tested animals and/ 

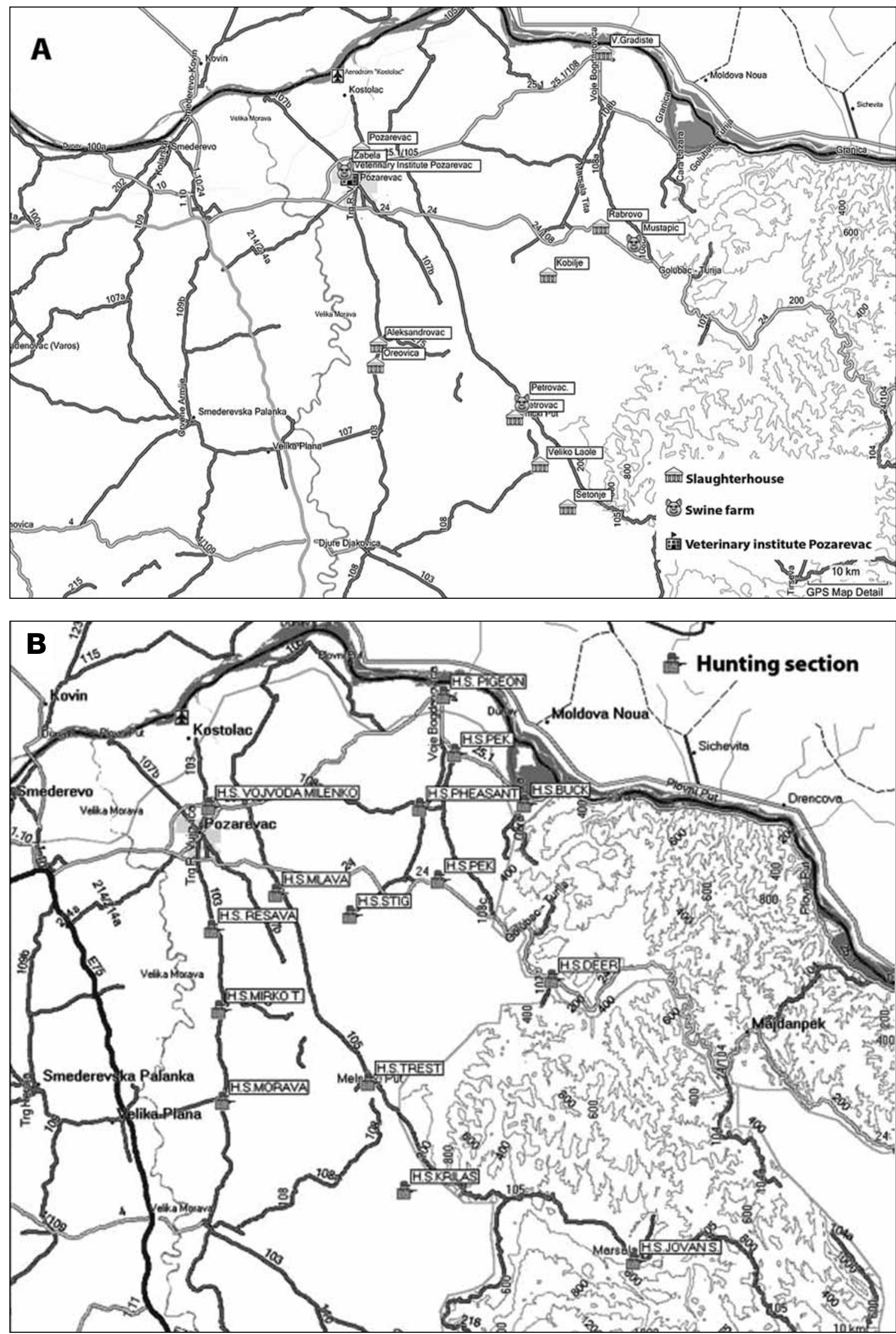

Fig. 2. - Geographical location of important veterinary facilities and hunting sections in Branicevo region. (A) Industrial, swine farms ( $\mathrm{n}=3$ ); Slaughterhouses $(n=12)$ with proper meat inspection for presence of Trichinella; $(B)$ Hunting sections $(n=15)$. 
or insufficient data on the landcover characteristics) for Serbia and few other European countries. Therefore, results presented in this paper are of both practical and scientific value.

When infected swine are detected, it is mandatory by the Serbian veterinary regulations (Official Journal SRJ 20/1995) to conduct sero-epizootiological investigations in all endangered animals in the endemic area. Such investigations can be best planned, using GIS-derived spatial and temporal patterns of Trichinella infection in the areas in question. Serological examinations are useful for epizootiological investigations and preparation of surveillance programs in areas where the prevalence of Trichinella infected animals is high (Gamble et al., 2004). According to the most important risk factors for trichinellosis in the domestic and sylvatic cycles (Pozio, 2007), many are present in the endemic district of Branicevo, and include intentional feeding of food waste containing pork scraps, scavenging on garbage dumps by pigs and dogs, and disposing of animal carcasses in the field which allows sylvatic animals to scavenge on carcasses of infected domestic swine and increases the probability of transmission to new hosts. GIS technology can be used for research of human and animal trichinellosis. Information that should be collected and related in a spatial context in order to draw relevant conclusions includes management of epidemic events (Trichinella infection in animals, human cases, connections between human outbreaks and animal infection), epizootiological surveillance (determination of infected animal species, investigation of endemic district, control program for certification of Trichinella free farms), and scientific investigations (determination of Trichinella species in an examined area).

In conclusion, the reported first application of GIS in Serbia is expected to facilitate trichinellosis surveillance and monitoring of Trichinella spp. circulation among domestic pigs, and populations of synanthropic and sylvatic animals.

\section{REFERENCES}

Blaga R., Durand B., Stoichici A., Gherman C., Stefan N., Cozma V. \& Boireau P. Animal Trichinella infection in Romania: Geographical heterogeneity for the last 8 years. Veterinary Parasitology, 2009, 159, 290-294.

Burke R., Masuoka P. \& MurRell K.D. Swine Trichinella infection and geographic information system tools, Emerging Infectious Diseases, 2008, 14, 1109-1111.

Cuperlovic K., Djordjevic M. \& Pavlovic S. Re-emergence of trichinellosis in southeastern Europe due to political and economic changes. Veterinary Parasitology, 2005, 132, 159-166.

Gamble H.R., Pozio E., Bruschi F., Nockler K., Kapel C.M.O. \& GAJADHAR A.A. International Commission on
Trichinellosis: recommendations on the use of serological tests for the detection of Trichinella infection in animals and man. Parasite, 2004, 11, 3-13.

Haghdoost A.A., Kawaguchi L., Mirzazadeh A., Rashidi H., SARAFINEJAD A., BANISADI A.R. \& DAvies C. Using GIS in explaining spatial distribution of Brucellosis in an endemic district in Iran. Iranian Journal of Public Health, 2007, 36, 27-34.

Pozio E. Taxonomy, biology and epidemiology of Trichinella parasites. Guidelines for the surveillance, management, prevention and control of trichinellosis. FAO/WHO/OIE, 2007, 31-35.

Pozio E., Rinaldi L., Marucci G., Musella V., Galati F., Cringoli G., Boireau P. \& La Rosa G. Hosts and habitats of Trichinella spiralis and Trichinella britovi in Europe. Inernational Journal for Parasitology, 2009, 39 (1), 71-79.

Rinaldi L., Biggeri A., Carbone S., Musella V., Catelan D, Veneziano V. \& Cringoli G. Canine faecal contamination and parasitic risk in the city of Naples (southern Italy), BMC. Veterinary Research, 2006, 2, 29.

Rinaldi L., Musella V., Biggeri A \& Cringoli G. New insights into the application of geographical information systems and remote sensing in veterinary parasitology. Geospatial Health, 2006, 1, 33-47.

Zivojinovic M., Dimitrijevic G., Lazic M., Petrovic M. \& SOFRONIC-Milosavljevic LJ. Trichinella prevalence in swine in an endemic district in Serbia: Epidemiology and control. Veterinary Parasitology, 2009, 159, 358-360.

Reçu le 6 mai 2010 Accepté le 17 juin 2010 